\title{
Multidetector Computed Tomography Angiography in the Follow-up of Surgical Treated Patients with Multiple Intracranial Aneurysms
}

Vania Bozhidarova Georgieva ${ }^{1}$, Emil Dimitrov Krastev¹, Emiliyan Iliev Gagov², Nikolay Dinev Georgiev ${ }^{1}$ and Ivan Stefanov Tsandev ${ }^{2}$

1. Department of Neurosurgery, Sofiamed Hospital, Sofia University St. Kliment Ohridski, Sofia 1000, Bulgaria

2. Department of Radiology, N. I. Pirogov Hospital, Medical University Sofia, Sofia 1000, Bulgaria

\begin{abstract}
OBJECTIVE: The purpose of this study was to assess the usefulness of MDCT (multidetector computed tomography) angiography as a routine follow-up examination of surgically treated patients with multiple intracranial aneurysms. METHODS: Thirty seven patients with a total of 92 multiple intracranial aneurysms underwent MDCT angiography to evaluate residual aneurysm remnants and de novo aneurysm formation. The mean period between aneurysm surgery and MDCT angiography examination was 8.9 years. The investigations were assessed by an experienced radiologists and neurosurgeons. RESULTS: Eight patients (21.6\%) showed abnormal findings on follow-up MDCT angiography: aneurysm remnants (5.4\%) and de novo formed aneurysms (18.9\%). Three of them were operated: one for reposition of the placed clips and two were treated by direct clipping of de novo formed aneurysm. Two patients were suitable for endovascular treatment. CONCLUSION: MDCT angiography is an useful routine examination for long-term follow-up of surgically treated patients with multiple intracranial aneurysms.
\end{abstract}

Key words: Multiple intracranial aneurysms, de novo aneurysms, MDCT (multidetector computed tomography) angiography, DSA (digital subtraction angiography).

\section{Introduction}

Long-term angiographic follow-up on patients operated for cerebral aneurysms is necessary, because of the risks associated with the presence of residual aneurysm structures and the developing of de novo aneurysms. The risk of hemorrhage in cases of partial aneurysm clipping and aneurysm rests outside the clip according to literature is from $0.5 \%$ to $1.9 \%$ per year [1]. The frequency of residual aneurysm structures in patients after surgical clipping varies between 3.8\% and $8 \%$ [2-4]. On the other hand, routinely used postoperative DSA (digital subtraction angiography) additionally increases the risks and makes the treatment more expensive. Because of this in a large part of neurosurgical departments, the use of

Corresponding author: Vania Bozhidarova Georgieva, M.D., research fields: neurosurgery, vascular neurosurgery and neuroradiology. E-mail: docvania@abv.bg. intraoperative and postoperative digital subtraction angiography is limited only for the cases with neurological complications after operative procedures [5, 6]. Noninvasive methods, such as CT (computed tomography) angiography and MRI (magnetic resonance imaging) angiography are used recently to follow-up the patients undergoing neurosurgical clipping of aneurysms [7-11].

There are publications reporting that MDCT (multidetector computed tomography) angiography can substitute DSA as primary diagnostic tool in the examination of patients with subarachnoid hemorrhage $[12,13]$. This is the statement of the systematic studying founded on the meta-analysis and assessment of the quality of the methodology based on Quality Assessment of Diagnostic Accuracy Studies [14]. In the literature database, however, there is little information about whether MDCT angiography could 
be used for long-term follow-up after surgical treatment of cerebral aneurysms.

\section{Materials and Methods}

During a period of nineteen years 510 patients with intracranial aneurysms were operated in two hospitals: "Queen Yoanna" (1991-1999) and "N. I. Pirogov" (2000-2010). Multiple cerebral aneurysms (174) were diagnosed and treated in 68 of the patients $(13.33 \%)$. From a total of sixty patients who have survived the operations, fifty four (90\%) were visited in their homes during 2010-2011. A follow-up MDCT angiography was performed in 37 of the visited patients. A total number of 92 aneurysms were evaluated. The mean period between aneurysm surgery and MDCT angiography examination was 8.9 years. The purpose of the investigations was to evaluate the state of the intracranial vessels, to identify the residual aneurysmal parts and the presence of de novo formed aneurysms.

The follow-up MDCT angiographies were carried out on a multi-slice computed tomography scanner (Siemens Somatom Definition AS). The CT scans were performed according to the established protocol of pre monitoring and monitoring with intravenous administration of a contrast agent (Omnipaque 350 $\mathrm{mg} / \mathrm{mL}$ ). The CT scanner parameters were: $100 \mathrm{KV}$, $175 \mathrm{~mA}, 0.6 \mathrm{~mm}$ collimation, rotation period $-0.5 \mathrm{sec}$. The information from the images has been processed on computer software (Siemens Syngo workstation), which allowed a 3D (three-dimensional) reconstruction and evaluation of the carotid and the vertebrobasilar vascular systems of the brain at different angles and rotations. The results from the control MDCT angiographies were interpreted by two radiologists (E.G., I. T.) and two neurosurgeons (E.K., V.G.). The follow-up MDCT angiographies and preoperative digital subtraction angiographies of the patients were comparatively evaluated for a residual aneurismal part and de novo aneurysm formation.

\section{Results and Analysis}

During the mean follow-up period of 8.9 years (from 0.5 to 19.75 years), 8 of the 37 patients (21.6\%), who have been diagnosed with multiple cerebral aneurysms, had pathological findings on the MDCT angiographies. The clinical symptoms, MDCT angiography findings and therapeutic approach in the patients with residual aneurism part outside the clip and de novo formed aneurysms are reviewed in Table 1. In the group of the 8 patients with pathological findings on the follow-up MDCT angiographies, women predominate over men ( 5 versus 3 ). The average age of the patients was 53.4 years (between 44 and 62).

The pathological signs in the eight patients on the follow-up MDCT angiographies were: (1) A residual aneurysm sac out of the clip —one case (Fig. 1); (2) A residual aneurysm neck outside the clip and a de novo aneurysm formation-one case (Fig. 2); (3) A formation of de novo aneurysm - six cases (Fig. 3).

Seven patients (18.9\%) were diagnosed with de novo formed aneurysms, arising from the following vessels: internal carotid artery in five cases, middle cerebral artery in one case and anterior cerebral artery in one case. In two cases $(5.4 \%)$ residual aneurysm parts were located at the bifurcation of the middle cerebral artery. There were no clinical symptoms or evidences for re-bleeding from any of the residual aneurysm parts or de novo formed aneurysms. The clinical symptoms were considered to be result of the initial aneurysm rupture. This gave an oppertunity to undertake a preventive treatment (embolization or surgical clipping) in five of the patients, in order to avoid the fatal consequences of a possible new subarachnoid hemorrhage.

In four of the patients, the follow-up MDCT angiography found contrast filling of previously, unruptured aneurysms ( 8 in number). There was no evidence of aneurysm enlargement among them. Three of the aneurysms have been wrapped, because of their small sizes, which did not allow the application of clip or endovascular embolization. In one case, due to the 


\section{Multidetector Computed Tomography Angiography in the Follow-up of Surgical Treated Patients with Multiple Intracranial Aneurysms}

Table 1 Clinical symptoms, CT angiography findings and therapeutic approach in patients with residual aneurysm part outside the clip and de novo formed aneurysms.

\begin{tabular}{|c|c|c|c|c|c|c|c|}
\hline Sex, Age & $\begin{array}{l}\text { Multiple intracranial } \\
\text { aneurysms locations }\end{array}$ & $\begin{array}{l}\text { Initial } \\
\text { intervention }\end{array}$ & $\begin{array}{l}\text { Follow-up } \\
\text { years }\end{array}$ & Symptoms & $\begin{array}{l}\text { Residual } \\
\text { aneurysm part }\end{array}$ & $\begin{array}{l}\text { De novo formed } \\
\text { aneurysms }\end{array}$ & $\begin{array}{l}\text { Subsequent } \\
\text { intervention }\end{array}$ \\
\hline & Right MCA bifurcation & Clipping & & & & & \\
\hline Female, 44 & $\begin{array}{l}\text { Right ICA bifurcation } \\
\text { Right ICA-choroid part }\end{array}$ & $\begin{array}{l}\text { Clipping } \\
\text { Clipping }\end{array}$ & 0.5 & Bradypsychia & $\begin{array}{l}\text { Left MCA } \\
\text { bifurcation }\end{array}$ & No & $\begin{array}{l}\text { Reposition } \\
\text { of the clip }\end{array}$ \\
\hline & $\begin{array}{l}\text { Left MCA-M1 segment } \\
\text { Left MCA bifurcation }\end{array}$ & $\begin{array}{l}\text { Clipping } \\
\text { Clipping }\end{array}$ & & & & & \\
\hline Female, 52 & $\begin{array}{l}\text { Right MCA bifurcation } \\
\text { Left MCA bifurcation }\end{array}$ & $\begin{array}{l}\text { Clipping } \\
\text { Clipping }\end{array}$ & 19.75 & $\begin{array}{l}\text { Aphasia, } \\
\text { Apraxia }\end{array}$ & $\begin{array}{l}\text { Right MCA } \\
\text { bifurcation }\end{array}$ & $\begin{array}{l}\text { Right ICA/ } \\
\text { PcomA }\end{array}$ & Follow-up \\
\hline Female, 51 & $\begin{array}{l}\text { Left ICA: } 3 \text { aneurysms } \\
\text { Right ICA - cavernous part }\end{array}$ & $\begin{array}{l}\text { Trapping } \\
\text { Follow-up }\end{array}$ & 6.25 & Intact & No & $\begin{array}{l}\text { Right } \\
\text { ICA-ophthalmic } \\
\text { part }\end{array}$ & Follow-up \\
\hline Male, 60 & $\begin{array}{l}\text { AcomA } \\
\text { Right MCA-M2 segment }\end{array}$ & $\begin{array}{l}\text { Clipping } \\
\text { Clipping }\end{array}$ & 5.8 & Intact & No & $\begin{array}{l}\text { Right } \\
\text { ICA/PcomA }\end{array}$ & $\begin{array}{l}\text { Endovascula } \\
\mathrm{r} \text { threatment }\end{array}$ \\
\hline Female, 48 & $\begin{array}{l}\text { Left MCA bifurcation } \\
\text { Right MCA bifurcation }\end{array}$ & $\begin{array}{l}\text { Clipping } \\
\text { Clipping }\end{array}$ & 8.1 & Intact & No & $\begin{array}{l}\text { Left ACA-A } 1 / 2 \\
\text { segments }\end{array}$ & Clipping \\
\hline Male, 51 & $\begin{array}{l}\text { AcomA } \\
\text { Right } \mathrm{MCA}-\mathrm{M} 1 \text { segment }\end{array}$ & $\begin{array}{l}\text { Clipping } \\
\text { Clipping }\end{array}$ & 9.6 & Intact & No & $\begin{array}{l}\text { Left MCA-M1 } \\
\text { segment }\end{array}$ & Follow-up \\
\hline & Left ICA/PcomA & Clipping & & & & Left & \\
\hline Male, 62 & $\begin{array}{l}\text { Left MCA bifurcation } \\
\text { AcomA }\end{array}$ & $\begin{array}{l}\text { Clipping } \\
\text { Clipping }\end{array}$ & 14.7 & Intact & No & $\begin{array}{l}\text { ICA-ophthalmic } \\
\text { part }\end{array}$ & Clipping \\
\hline Female, 59 & $\begin{array}{l}\text { Right MCA } \\
\text { Left MCA }\end{array}$ & $\begin{array}{l}\text { Clipping } \\
\text { Clipping }\end{array}$ & 11 & Intact & No & Left ICA/PcomA & $\begin{array}{l}\text { Endovascula } \\
\mathrm{r} \text { threatment }\end{array}$ \\
\hline
\end{tabular}

AcomA — anterior communicating artery; ICA —internal carotid artery; MCA — middle cerebral artery; ACA — anterior cerebral artery; PcomA - posterior communicating artery.
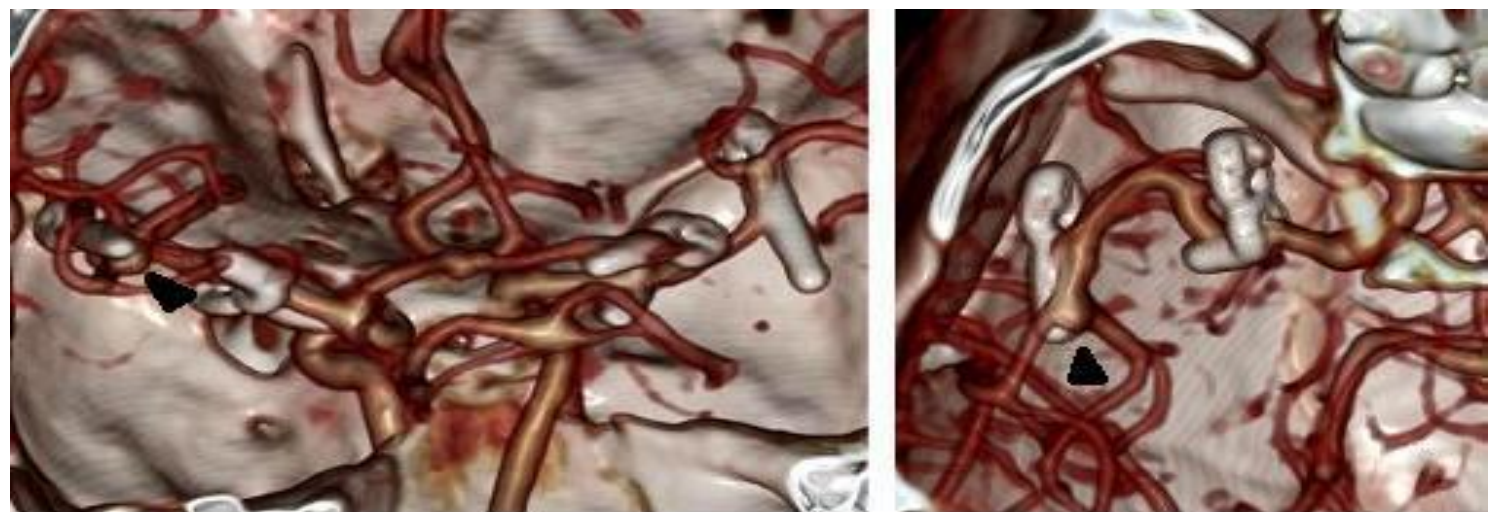

Fig. 1 MDCT angiography with signs of a residual aneurysm sac $(\Delta)$ after clipping left middle cerebral artery bifurcation aneurysm.
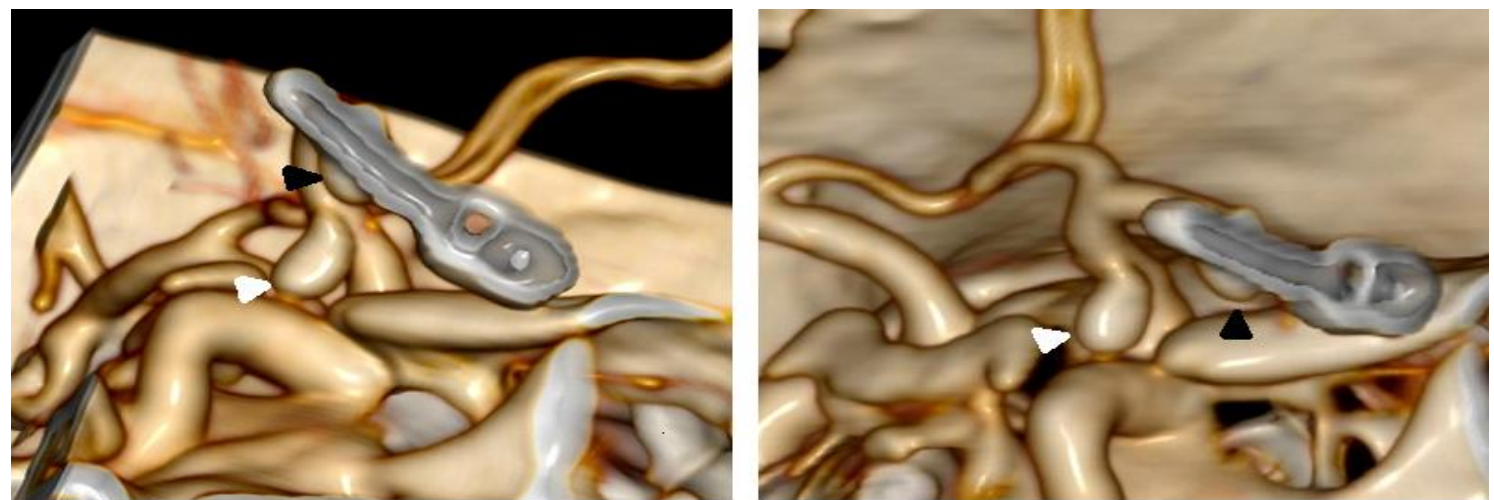

Fig. 2 MDCT angiography with signs of a residual aneurysm neck $(\Delta)$ and de novo formed right internal carotid artery $\operatorname{aneurysm}(\Delta)$. 

Surgical Treated Patients with Multiple Intracranial Aneurysms

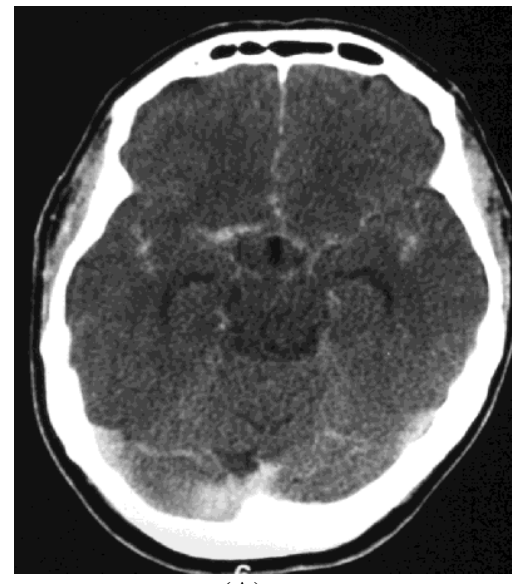

(A)

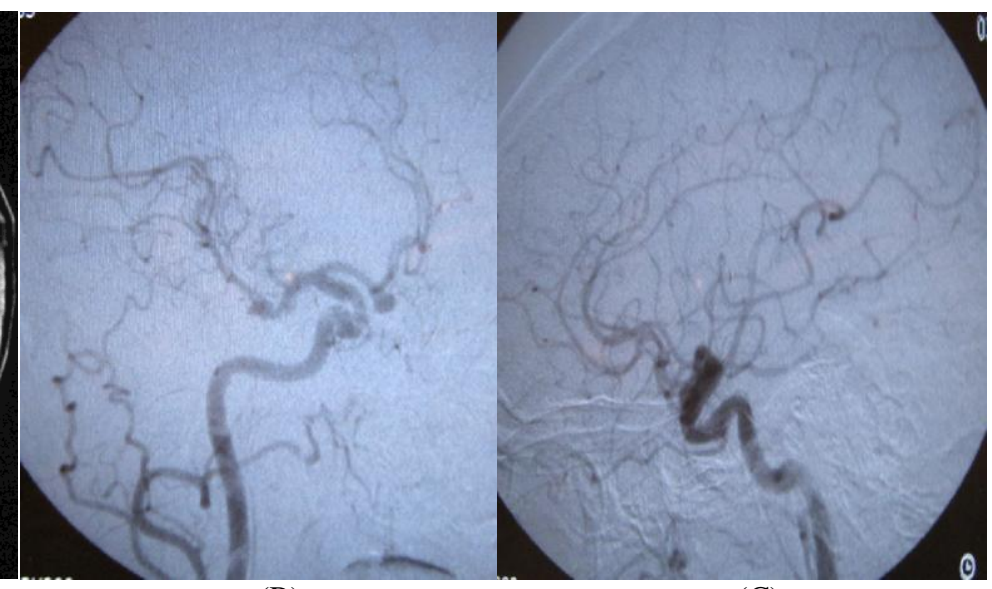

(B)
(C)

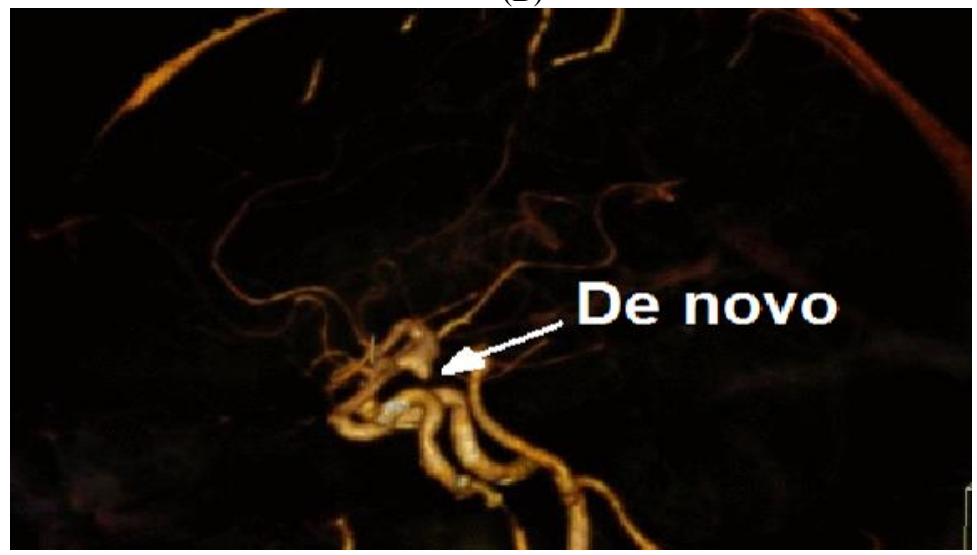

(D)

Fig. 3 Native CT with signs of subarachnoid hemorrhage (A) and DSA (B, C) of a patient in 2005-two aneurysms on the right middle cerebral artery and the anterior cerebral artery were identified. MDCT angiography of the same patient (D) in 2011 - an aneurysm of right internal carotid artery was identified.

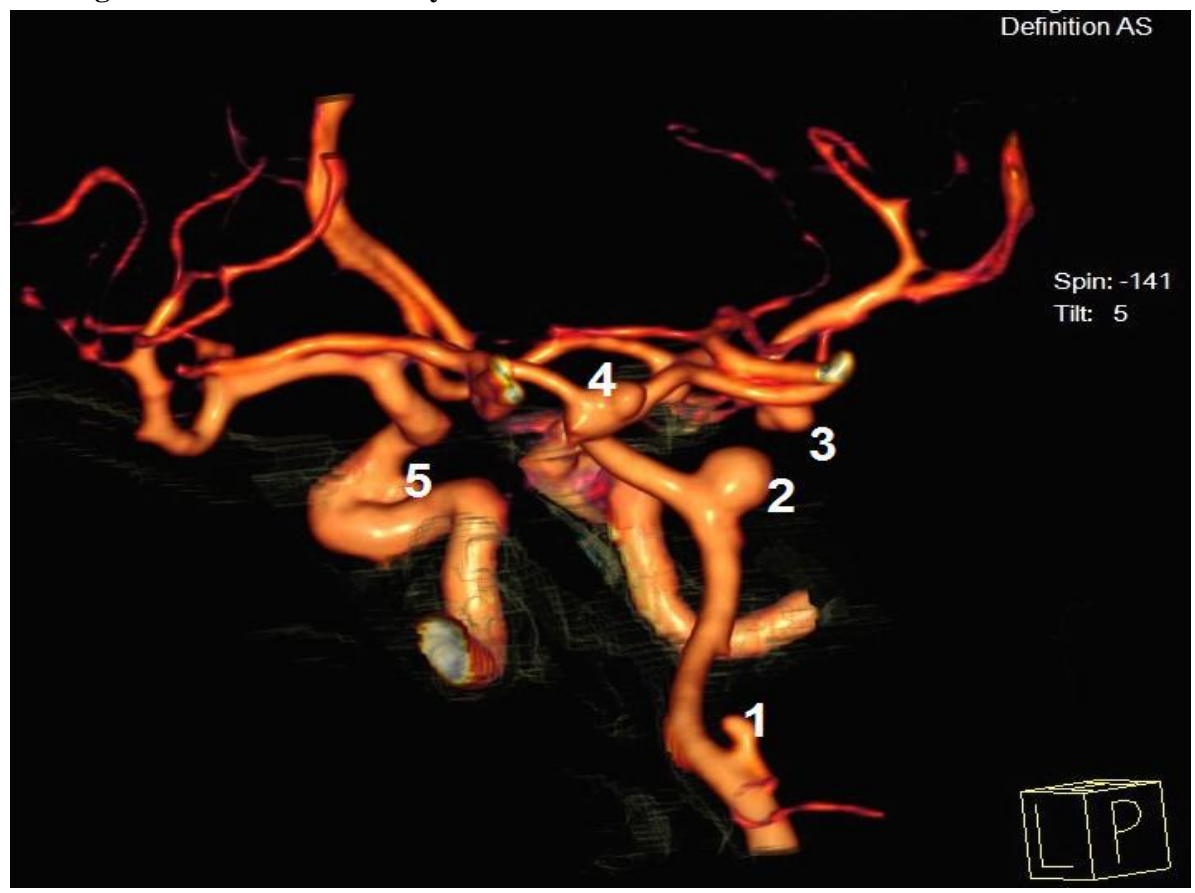

Fig. 4 MDCT angiography of a patient with multiple cerebral aneurysms (3D reconstruction). 
large number of aneurysms, involving anterior and posterior circulations of the brain, only the ruptured aneurysm on the internal carotid artery was clipped. The rest five unruptured aneurysms were followed up and there was no evidence of bleeding during 15 years of follow (Fig. 4).

In the current series of 92 multiple intracranial aneurysms in 37 patients, complete obliteration and isolation were achieved in 82 of the aneurysms (89.1\%). In the presence of noninvasive methods for postoperative monitoring of the effectiveness of clipping and de novo aneurysm formation, and after a decision for conservative follow-up of the unruptured aneurysms, most of the patients refused conventional angiography. In the cases of diagnostic uncertainty from noninvasive examination-MDCT angiography, we have been insisting on performing a digital subtraction angiography. Additionally, DSA was performed in four patients, but the diagnostic value did not outweigh the one from the MDCT angiographies.

\section{Discussion}

DSA, as a method for long-term follow-up of patients operated for cerebral aneurysms is associated with a risk of corresponding, angiographic complications and makes the treatment more expensive. Neurological complications during conventional cerebral angiography in the different scientific reports range from $0.4 \%$ to $12.2 \%$ [15-18]. Because of this, DSA can not be used routinely for long-term follow-up, especially in the presence of new, noninvasive methods for angiographic control. Kassel suggests that the postoperative DSA can be done in the following cases [3]: (1) all the patients with a new, unexplained postoperative neurological deficit; (2) all the patients with a difficulties at the time of the surgery.

The present study is the first of its kind in our country. The results indicate that MDCT angiography is a convenient, noninvasive examination method for a routine, long-term follow-up of patients, operated for cerebral aneurysms. The use of narrowly collimated beam over the area of interest reduces the metal artifacts of the clips. This gives the opportunity to visualize the vessels in proximity to the clips, including the presence of possible residual aneurysm structures.

Important advantages of the MDCT angiography are: (1) shorter time comparing to DSA; (2) 3D images allow $360^{\circ}$ rotation with more complete images of residual aneurysm structures and the adjacent vessels; (3) the lack of risk of angiographic complications.

\section{Conclusion}

The research is one of the first of its kind. The authors estimate $18.9 \%$ frequency for de novo aneurysm formation in series of patients with multiple intracranial aneurysms during 8.9 years follow-up period. MDCT angiography can be used as a primary screening investigation in the long-term follow-up of patients, who were operated for multiple intracranial aneurysms. MDCT angiography appears to be a promising postoperative routine investigation after aneurysm clipping.

\section{References}

[1] David, C. A., Vishteh, A. G., Spetzler, R. F., Lemole, M., Lawton, M. T., and Partovi, S. 1999. "Late Angiographic Follow-up Review of Surgically Treated Aneurysms.' Journal of Neurosurgery 91 (3): 396-401.

[2] Feuerberg, I., Lindquist, C., Lindqvist, M., and Steiner, L. 1987. "Natural History of Postoperative Aneurysm Rests.' Journal of Neurosurgery 66 (1): 30-34.

[3] Kassell, N. F., and Boarini, D. J. 1984. "Perioperative Care of the Aneurysm Patient.' Contemporary Neurosurgery 6: 1-6.

[4] Sindou, M., Acevedo, J. C., and Turjman, F. 1998. "Aneurysmal Remnants after Microsurgical Clipping: Classification and Results from Prospective Angiographic Study (in a Consecutive Series of 305 Operated Intracranial Aneurysms)." Acta Neurochirurgica (Wien) 140 (11): 1153-9.

[5] Harbaugh, R. E., Heros, R. C., and Hadley, M. N. 2003. "More on ISAT." Lancet 361 (9359): 83-4.

[6] Tang, G., Cawley, C. M., Dion, J. E., and Barrow, D. L. 2002. "Intraoperative Angiography during Aneurysm Surgery: A Prospective Evaluation of Efficacy." Journal of Neurosurgery 96 (6): 993-9.

[7] Dehdashti, A. R., Binaghi, S., Uske, A., and Regli, L. 2006. 
"Comparison of Multislice Computerized Tomography and Digital Subtraction Angiography in the Postoperative Evaluation of Patients with Clipped Aneurysms.' Journal of Neurosurgery 104 (3): 395-403.

[8] Lee, J. H., Kim, S. J., Cha, J., Kim, H. J., Lee, D. H., Suh, D. C., and Ahn, J. S. 2005. "Postoperative Multidetector Computed Tomography after Aneurysm Clipping: Comparison with Digital Subtraction Angiography." Journal of Computer Assisted Tomography 29 (1): 20-5.

[9] Sakuma, I., Tomura, N., Kinouchi, H., Takahashi, S., Otani, T., Watarai, J., and Mizoi, K. 2006. "Postoperative Three-dimensional CT Angiography after Cerebral Aneurysm Clipping with Titanium Clips: Detection with Single Detector CT-comparison with Intraarterial Digital Subtraction Angiography." Clinical Radiology 61 (6): 505-12.

[10] Teksam, M., McKinney, A., Cakir, B., and Truwit, C. L. 2004. "Multi-slice Computed Tomography Angiography in Detection of Residual or Recurrent Cerebral Aneurysms after Surgical Clipping.” Acta Radiologica 45 (5): 571-6.

[11] van Loon, J. J., Yousry, T. A., Fink, U., Seelos, K. C., Reulen, H. J., and Steiger, H. J. 1997. "Postoperative Spiral Computed Tomography and Magnetic Resonance Angiography after Aneurysm Clipping with Titanium Clips." Neurosurgery 41 (4): 851-6.

[12] Ivanov, I., Petkov, A., Lilov, M., Eftimov, T., Hadjiangelov, I., Nikolov, V., Nikolov, I., Prancheva, B., Kisiova, I., and Gorcheva, S. 2006. "Computed Tomography Angiography in Patients with Aneurysmal Subarachnoid Hemorrhage." Roentgenology and
Radiology 45 (4): 263-8.

[13] Velthuis, B. K, van Leewen, M. S., Witkamp, T. D., Ramos, L. M., van der Sprenkel, J. W. B., Ringel, and G. J. 1999. "Computerized Tomography Angiography in Patients with Subarachnoid Hemorrhage: From Aneurysm Detection to Treatment without Conventional Angiography." Neurosurgery 91 (5): 761-7.

[14] Westerlaan, H. E., van Dijk, J. M. C., Marijke C., Jansen-van der Weide, M. C., de Groot, J. C., Groen, R. J. M., Mooij, J. J. A., and Oudkerk, M. 2010. "Intracranial Aneurysms in Patients with Subarachnoid Hemorrhage: CT Angiography as a Primary Examination Tool for Diagnosis-Systematic Review and Metaanalysis.” 2010. Radiology 258 (1): 134-45.

[15] Waugh, J. R., and Sacharis, N. 1992. "Arteriographic Complications in the DSA Era.” Radiology 182 (1): 243-6.

[16] Hankey, G. J., Warlow, C. P., and Sellar, R. J. 1990. "Cerebral Angiographic Risk in Mild Cerebrovascular Disease.” Stroke. 21 (2): 209-22.

[17] Willinsky, R. A., Taylor, S. M., TerBrugge, K., Farb, R. I., Tomlinson, G., and Montanera, W. 2003. "Neurologic Complications of Cerebral Angiography: Prospective Analysis of 2,899 Procedures and Review of the Literature." Radiology 227 (2): 522-8.

[18] Connors, J. J., Sacks, D., Furlan, A. J., Selman, W. R., Russel, E. J., Stieg, P. E., and Hadley, M. N. 2004 "Training, Competency and Credentialing Standards for Diagnostic Cervicocerebral Angiography, Carotid Stenting, and Cerebrovascular Intervention." American Journal of Neuroradiology 25 (10): 1732-41. 